\title{
The Association Between Positive Religious Coping, Perceived Stress, and Depressive Symptoms During the Spread of Coronavirus (COVID-19) Among a Sample of Adults in Palestine: Across Sectional Study
}

\author{
Fayez Azez Mahamid ${ }^{1}$ (D) Dana Bdier ${ }^{1}$
}

Accepted: 23 October 2020 / Published online: 2 January 2021

(c) Springer Science+Business Media, LLC, part of Springer Nature 2021

\begin{abstract}
Objectives The current study was designed to investigate the relationship between positive religious coping, perceived stress, and depressive symptoms among Palestinian adults in response to the emergence of coronavirus (COVID-19), and the quarantine system implemented in the city of Tulkarem, Palestine.

Methods A correlational study was conducted to examine the relationship between study variables. Participants were 400 Palestinian adults, involving 172 males and 228 females, living in the city of Tulkarem, Palestine, during the spread of coronavirus. Participants were selected using convenience and snowball sampling techniques. Results Pearson's correlation coefficient was used to test the relationship between positive religious coping, depressive symptoms, and perceived stress. Findings revealed a statistically significant negative correlation between positive religious coping and depressive symptoms $(r=-.17, p<.01)$. Results also indicated a statistically significant negative correlation between positive religious coping and perceived stress $(r=-.15, p<.01)$. The regression analysis for predicting depressive symptoms found that both positive religious coping $(B=-.21, \mathrm{SE}=.05, \beta=-.18)$ and perceived stress $(B=.41, \mathrm{SE}=.05, \beta=.35)$ were statistically significant toward explaining variance in depressive symptoms.

Conclusion The importance of developing intervention programs that take into consideration religious/spiritual struggles and positive religious strategies may help improve resilience and well-being among affected populations. With the recent spread of COVID-19, findings of this current study have presented important practical implications for improving the mental health and well-being among Palestinians, especially since Palestinian society continues to face different types of stressors, such as illegal occupation. Further studies are recommended to test the relationship between current study variables and other related variables.
\end{abstract}

Keywords Positive religious coping - Perceived stress - Depressive symptoms · COVID-19 $\cdot$ Palestine

Extended author information available on the last page of the article 


\section{Introduction}

On January 6, 2020, a novel coronavirus emerged and was termed COVID-19 (Pan et al. 2020). In general, COVID-19 is an acute respiratory disease that could also be deadly, with a $2 \%$ case fatality rate. It is categorized by several symptoms including fever, chills, cough, fatigue, and shortness of breath (Xu et al. 2020).

The World Health Organization (WHO) declared COVID-19 a public health emergency of international concern as of February 1, 2020 (Sohrabi et al. 2020). As of August 24, 2020, a total of 23,311,719 cases, including 806,410 deaths, were confirmed. Various Middle Eastern and Arab Gulf countries were found to have COVID-19 cases such as Lebanon with 12,698 cases, Oman with 83.769 cases, Qatar with 117,008 cases, Saudi Arabia with 307,479 cases, Jordan with 1609 cases, and Palestine with 25,024 cases (WHO 2020).

As with any epidemic, COVID-19 may impose several psychological risk factors on individuals who reside in the infected areas such as depression, stress, and anxiety (De Quervain et al. 2020; Qiu et al. 2020). According to the behavioral immune system (BIS) theory, during epidemics, people are more likely to develop negative emotions (e.g., aversion, anxiety, etc.), as well as negative cognitive assessment toward self-protection. Furthermore, according to stress and perceived risk theories, public health emergencies trigger increased negative emotions that also affect cognitive assessment ( $\mathrm{Li}$ et al. 2020).

Moreover, as individuals are required to stay at home, or self-quarantine, growing feelings of isolation and social separation may take over their thoughts, which as research shows, is found to have negative impacts on psychological well-being (Ammerman et al. 2020). People under quarantine were found to suffer from different mental health problems such as depression, anxiety, mood disorders, psychological distress, posttraumatic stress disorder(PTSD), insomnia, and fear (Hossain et al. 2020).

Fear of the unknown along with thoughts of becoming infected increased anxiety and stress levels in healthy individuals and intensified the symptoms of those with pre-existing psychological disorders (Ornell et al. 2020). The closures of schools, companies, and public places, changes to work and daily routines, along with the loss of different supplies such as food and medications, raised levels of stress, anxiety, and depression among individuals in the infected areas (Stankovska et al. 2020).

Since it is predicted that COVID-19 may have negative psychological issues such as depression and perceived stress, it is incumbent upon societies to investigate possible factors which may relate to these issues. For people in geopolitically at-risk environments, such as Palestine, the situation is far more complex (Mahamid 2020; Mahamid and Berte 2020a).

People residing in the occupied territories of Palestine have high levels of environmental stressors (e.g., militarization, poverty, lack of employment opportunities, cultural pressures, etc.) and fewer positive social outlets due to the restrictions on movement between communities, a lack of recreational facilities, and cultural standards of gender separation. In this situation, the spread of 
coronavirus in Palestine could lead to maladaptive and depressive symptoms in the face of heightened stressors and few intervention avenues (Mahamid and Berte 2019, 2020b).

One of the predicted protective factors for the mentioned issues is positive religious coping. Previous literature found positive religious coping as a protective factor for several psychological disorders such as depression, anxiety, and PTSD (Assari 2014; Carpenter et al. 2012; Feder et al. 2013; $\mathrm{Ng}$ et al. 2017). Positive religious coping was also found to have a positive relationship with health-related issues concerning quality of life (Cruz et al. 2016; Henslee et al. 2015; Pedersen et al. 2013).

\section{Theoretical Background}

\section{Religious Coping}

Religion can be a positive force for physical and mental health. However, religion also has its "seamy side" and may potentially exacerbate problems (Pargament et al. 2001). For example, positive religious coping activities reflect a secure attachment to God, a belief that life has an ultimate meaning, and a sense of spiritual connectedness with others, while negative religious coping methods reflect a shaken worldview and are characterized by religious conflict and strain (Abu-Raiya et al. 2019).

Religious coping could be best defined as the beliefs or behaviors that are used to deal with problems when adverse circumstances exceed the limits of resources (Lee et al. 2014). According to dispositional and situational theories of coping, individuals are predisposed to respond to stressors with a preferred coping strategy that remains relatively consistent across a range of situations. Similarly, religious coping typically has been conceptualized in terms of dispositions or traits that describe the extent and manner in which an individual's faith becomes involved in the problemsolving process (Schaefer and Gorsuch 1993).

Individuals who use positive religious coping are thought to be better able to adjust and to overcome stressors of life (Koenig et al. 1988). Moreover, they seem to have high levels of resilience toward depression and anxiety disorders (Min et al. 2013). On the contrary, individuals with negative religious coping seemed to become alcoholics and psychologically distressed (Chan and Rhodes 2013; Holt et al. 2014).

Islam is a religion in Palestine adhered to by the majority of its population. Muslims comprise $85 \%$ of the population of the West Bank, when including Israeli settlers, and account for $99 \%$ of the population in the Gaza Strip. Palestinian Muslims primarily practice Shafi'i Islam, which is a branch of Sunni Islam (Palestinian Central Bureau of Statistics 2019).

Palestinian society has high religiosity levels; $79 \%$ of Palestinians define themselves as religious, although the degree of religious observance varies (Azaiza and Cohen 2008). Even less religious Palestinians still largely uphold religious beliefs, for example, regarding the causes of illness or the fatalistic nature of life (Goldblatt et al. 2012). 
The Islamic faith provides many theological responses for dealing with crisis and difficult situations. For example, it encourages Muslim believers to accept the crisis and painful events as part of God's wise plan and view crisis as a test from God to deepen one's beliefs. On the other hand, it discourages people from "giving up on the mercy of God" and getting involved in self-harm activities (Almuhtaseb et al. 2020).

In respect to this study, religiosity may be considered as a protective factor if individuals face their fears and anxieties with complete trust in God and if they show patience and gratitude toward all circumstances, sadness, and worry (Ibrahim 2020). In addition, developing a deeper religious faith through prayer, reading holy books, and listening to inspirational programs may help individuals, since it was found that religious practices are associated with less anxiety, stress, and greater hope (Koenig 2020).

\section{Positive Religious Coping and Depressive Symptoms}

Studies on religiosity and depression support the conclusion that certain aspects involving religiosity correlate with less depression (Ahles et al. 2016; Braam et al. 2010). People who are frequently active in the religious community and attach great importance to their faith may be less at risk of falling into depression. Even when such people do experience depression, they can recuperate from it faster than people who are not religious. Religious involvement thus plays an important role in helping people cope with the effects of the pressures of life (Agbaria 2014).

Ramirez et al. (2012) assessed whether positive religious coping or religious struggle was independently associated with psychological distress and healthrelated quality of life in hemodialysis patients. They found that religious struggle correlated with both depressive and anxiety symptoms, while positive religious coping was associated with better overall mental and social relations. Moreover, religious struggles were found to be positively correlated with depressive symptoms among American adults (Abu-Raiya et al. 2015).

In addition, Areba et al. (2018) examined the associations between positive and negative religious coping, symptoms of depression and anxiety, physical and emotional well-being among Somali college students in Minnesota. Results showed that positive religious coping was associated with a decrease in symptoms of depression. Rosmarin et al. (2013) found that positive religious coping was associated with significantly greater reductions in depression and anxiety, and increases in well-being.

Kopacz et al. (2016) found that negative religious coping was associated with suicide risk and suicidal thoughts. On the other hand, the results showed that positive religious coping was related to higher levels of psychological well-being and lower levels of depression (Ahrens et al. 2010). In another study, Hashmi et al. (2020) found that negative religious cliché and stigma related to COVID-19 in some Islamic developing countries have resulted in avoiding the established precautionary measures against the disease. 


\section{Positive Religious Coping and Perceived Stress}

Perceived stress is defined as a condition subjectively experienced by an individual who identifies an imbalance between demands addressed to him/her and the resources available to encounter these demands (Lazarus 1990). According to the literature, there are different strategies to cope with perceived stress, and one of these strategies is positive religious coping. Arévalo et al. (2008) found that positive religious coping methods have been associated with less perceived stress. Furthermore, the results showed that religiosity was positively associated with peace, which in turn was positively and significantly associated with less stress (Peres et al. 2018).

Lee (2014) demonstrated that negative correlations existed between spiritual well-being and participants' perceived stress. In addition, positive religious coping was positively related to quality of life (QOL) and lack of stress, while negative religious coping was negatively related to the QOL and increased stress (Gardner et al. 2014).

As coronavirus, COVID-19, is a new epidemic, no study currently exists which has examined the risk factors or protective factors for depression and perceived stress related to the spread of COVID-19 in Palestine. This study attempts to explore the relationship between positive religious coping, depressive symptoms, and perceived stress among a sample of Palestinian adults who are living in an area with confirmed cases of COVID-19.

\section{The Study}

In regard to this study, Palestinians were found to seek spiritual support for overcoming the adversities and stressors, as previous studies have shown (Thabet et al. 2016; Thabet 2017). Furthermore, it was found that positive religious strategies and well-being were both correlated negatively with depression, as spiritual well-being was found to be very high among Palestinians (Abu-El-Noor and Radwan 2015; Abdel-Khalek and Eid 2011; Abu-El-Noor 2017).

The current study hypothesized that: (1) There would be a negative correlation between positive religious coping and depressive symptoms among Palestinian adults; (2) there would be a negative correlation between positive religious coping and perceived stress among Palestinian adults; and (3) there would be a positive correlation between perceived stress and depressive symptoms among Palestinian adults.

\section{Methodology}

\section{Participants}

Participants were selected using both convenience and snowball sampling techniques from among Palestinian adults in the city of Tulkarem during the spread of 
COVID-19. Tulkarem is a city located in the Northern region of Palestine; participants were 400 Palestinian adults, representing 172 males and 228 females (Table 1). A geographical representation of the participants showed that $53.0 \%$ of participants were from cities. $42.0 \%$ were from villages, and 5.0\% were from Palestinian camps.

The age demographic of participants showed that $45.3 \%$ were aged 20-29. 29.6\% were aged 30-39. 15.5\% were aged 40-49, and the remaining 9.8\% were aged 50-59. Inclusion in the study required participants to be: (1) Palestinian, (2) native Arabic speakers, and (3) from families who were in home quarantine during the spread of COVID-19. The study was submitted for review by An-Najah Institutional Review Board (IRB) and received approval before data collection was initiated.

\section{Instruments and Procedures}

\section{Psychological Measure of Islamic Religiousness Scale (PMIR)}

Positive religious coping was assessed by the IPRC subscale of the Psychological Measure of Islamic Religiousness (Abu-Raiya et al. 2008). The IPRC is composed of seven items (e.g., "I do what I can and put the rest in Allah's hands"). It is a 4-point scale ranging from 1 (I do not do this at all) to 4 (I do this a lot). Scores on this scale were tallied with higher scores reflecting more positive religious coping. For this scale, a Cronbach's coefficient ( $\alpha$ ) of .85 was found (Abu-Raiya et al. 2019.

\section{Center for Epidemiological Studies Depression Scale (CES-D-10)}

Depressive symptoms were measured by a 10-item version of the Center for Epidemiological Studies Depression Scale (Andresen et al. 1994). Participants rated the extent to which they experienced 10 depressive symptoms (e.g., "I felt sad"), on a 4-point scale

Table 1 Demographic characteristics of study sample $(N=400)$

\begin{tabular}{lcc}
\hline Characteristic & Number & $(\%)$ \\
\hline Gender & 172 & \\
Male & 228 & 43 \\
Female & 400 & 57 \\
Total & & 100 \\
Geographical region & 212 & \\
City & 168 & 53 \\
Village & 20 & 42 \\
Camp & 400 & 5 \\
Total & & 100 \\
Age & 181 & \\
$20-29$ & 118 & 45.3 \\
$30-39$ & 62 & 29.6 \\
$40-49$ & 39 & 15.5 \\
$50-59$ & 400 & 9.8 \\
Total & & 100 \\
\hline
\end{tabular}


ranging from rarely/none of the time (1) to most/all of the time (4). Items were summed with higher scores indicating higher depressive symptoms. For this scale, a Cronbach's coefficient ( $\alpha$ ) of .81 was found (Abu-Raiya et al. 2019).

\section{The Perceived Stress Scale (PSS)}

Perceived stress was tested by the perceived stress scale (PSS), developed by Cohen et al. (1983), and it consists of 10 items measure the degree to which situations in one's life are appraised as stressful. Items were designed to tap how unpredictable, uncontrollable, and overloaded respondents find their lives.

The questions in the PSS ask about feelings and thoughts during the last month. In each case, respondents are asked how often they felt a certain way. Examinees responded to each statement with a number from 1 to 5 on a Likert scale continuum, indicating the extent to which they endorse that particular belief. In order to test reliability of the scale, Cronbach's alpha formula used among a sample of 60 Palestinian university students' independent of the study sample (reliability sample), Cronbach's alpha coefficients indicated high level of reliability for the total scale (.80).

\section{Research Procedures}

Research was conducted in February 2020 and targeted Palestinian adults in the city of Tulkarem, located in North of Palestine. The sample recruited using convenience and snowball sampling techniques from among families who quarantined at home by order of the Palestinian Ministry of Health during the spread of COVID-19. One of the authors of this study, along with a team from the Ministry of Health, visited quarantined families at their homes and explained the aims of the research, with a focus on the voluntary nature of participation.

All participants were provided with information that enabled them to make informed decisions as to whether or not they wanted to participate in the research. They were provided with descriptions of the scales and the purpose of the research. Participants who agreed to participate in the research signed a formed consent. The research was conducted in line with the ethical guidelines of the American Psychological Association (APA 2010) and the Declaration of Helsinki (2013) and had been approved by the An-Najah National University IRB and the Palestinian Ministry of Health.

Study instruments were designed in such a way as to limit as much as possible emotional distress throughout the interview. The interviewer, a licensed mental health professional, was available to provide assistance should any participant become distressed during the survey. In addition, all participants were provided with contacts to mental health services through whom to seek help should symptoms arise subsequent to their participation in the research.

\section{Data Analysis}

To examine the degree of positive religious copying, perceived stress, and depressive symptoms among participants, means, standard deviations, and percentages 
Table 2 Means and standard deviations for research variables $(N=400)$

\begin{tabular}{lcccccrr}
\hline Variable & Mean & SD & Min & Max & Range & Skewness & Kurtosis \\
\hline Depressive symptoms & 22.39 & 5.35 & 13 & 36 & 23.00 & .520 & -.326 \\
Perceived stress & 30.06 & 4.65 & 18 & 42 & 24.00 & -.115 & .034 \\
Positive religious coping & 24.52 & 4.67 & 7 & 28 & 21.00 & -1.648 & 2.634 \\
\hline
\end{tabular}

Table 3 Correlations among study variables $(N=400)$

\begin{tabular}{llll}
\hline Measures & $(1)$ & $(2)$ & $(3)$ \\
\hline (1) Depressive symptoms & - & $.34^{* *}$ & $-.17^{*}$ \\
(2) Perceived stress & & - & $-.15^{* *}$ \\
(3) Positive religious coping & & & - \\
\hline
\end{tabular}

$* p<.05 ; * * p<.01$

were used. Pearson's correlation coefficient was also conducted to test the relationship between positive religious coping, perceived stress, and depressive symptoms among participants. The Pearson correlation coefficient, also known as the sample correlation coefficient (r), product-moment correlation coefficient, or coefficient of correlation, measures and interprets the linear relationship between two or more random variables (Zou et al. 2003).

The regression analysis was also performed to test the causal relationship between positive religious coping, perceived stress, and depressive symptoms; the purpose of regression analysis was to evaluate the relative impact of a predictor variable on a particular outcome (Zou and Hall 2002).

\section{Findings}

As Table 2 indicates, overall, the participants scored on average on depressive symptoms, with medium scores on perceived stress and high scores on positive religious coping.

As shown in Table 3, depressive symptoms were positively correlated with perceived stress, and also negatively correlated with positive religious coping, while perceived stress was negatively correlated with positive religious coping.

The data confirm Hypothesis 1 . Results of Table 3 showed a statistically significant negative correlation between depressive symptoms and positive religious coping $(r=-.17, p<.05)$, and the regression analysis for predicting depressive symptoms (Table 4) found that positive religious coping was contributed in a way that was statistically significant toward explaining variance in depressive symptoms $(B=-.21, \mathrm{SE}=.05, \beta=-.18)$.

Results also confirmed Hypothesis 2 . Table 3 shows a statistically significant negative correlation between positive religious coping and perceived stress $(r=-.15$, $p<.01$ ). The regression analysis for predicting depressive symptoms (Table 4 ) found 
Table 4 Regression to predict depressive symptoms $(N=400)$

\begin{tabular}{|c|c|c|c|c|c|c|}
\hline Variable & $B$ & SE & $B$ & $t$ & $p$ & $95 \% \mathrm{CI}$ \\
\hline Positive religious coping & -.211 & .05 & $-.184 * *$ & -4.06 & $.000 * *$ & {$[-.31$ to -.10$]$} \\
\hline Perceived stress & .411 & .05 & $.357 * *$ & 7.82 & $.000 * *$ & {$[.30$ to .51$]$} \\
\hline Gender & -.251 & 1.93 & -.005 & -.13 & .89 & {$[-4.06$ to 3.55$]$} \\
\hline Age & -.067 & 2.66 & -.001 & -.02 & .98 & {$[-5.30$ to 5.17$]$} \\
\hline Residency & .694 & .414 & -.077 & -1.67 & .09 & {$[-2.05$ to 2.57$]$} \\
\hline
\end{tabular}

that perceived stress contributed in a way that was statistically significant toward explaining variance in depressive symptoms $(B=.41, \mathrm{SE}=.05, \beta=.35)$. Hypothesis 3 was also confirmed. Table 3 shows a statistically significant positive correlation between perceived stress and depressive symptoms $(r=.34, p<.01)$.

\section{Discussion}

This study aimed to test the association between positive religious coping, depressive symptoms, and perceived stress during the spread of COVID-19 among a sample of adults in Palestine.

\section{Positive Religious Coping and Depressive Symptoms}

Positive religious coping was negatively associated with depressive symptoms, which supported the first hypothesis of research. These findings were in line with studies indicating that positive religious coping correlated negatively with depressive symptoms (Ahles et al. 2016; Carleton et al. 2008; Hebert et al. 2009; Lee et al. 2014; Feder et al. 2013; Ramirez et al. 2012).

In practicing positive religious coping, individuals who face stressful events may begin to perceive strength in their relationship with God, which may lead them to think positively toward stressful events, and may help them to deal with the deleterious impacts of depressive symptoms (Abu-Raiya et al. 2020). Depressed individuals are more likely to become socially withdrawn, exhibit excessive reassurance, and seek and express neediness for emotional support (Fernandez and Loukas 2013).

Strengthening their relationship with God may give depressed people a sense of support as well as the necessary guidance to face life's challenges, particularly during stressful circumstances. This relationship with God may diminish a depressed individual's need to withdraw and behave negatively by filling the void of social support that those with depressive symptoms often experience (Horton and Loukas 2013).

Fernandez and Loukas (2013) examined whether positive religious coping would moderate the association between perceived stress and depressive symptoms. Participants reported that in using positive religious coping, they felt protected from experiencing heightened levels of depressive symptoms when faced with stressful events. 
Abernethy et al. (2002) tested the relationship between positive religious coping and depression in spouses of lung cancer patients. Results showed a significant association between positive religious coping squared and depression; spouses who used moderate levels of positive religious coping were rated as less depressed than those who used lower or levels.

\section{Positive Religious Coping and Perceived Stress}

A negative relationship between positive religious coping and perceived stress, which supported the second hypothesis of this study, was consistent with earlier studies (Ano and Vasconcelles 2005; Gardner et al. 2014; Khan and Watson 2006; Maltby and Day 2003; Pargament et al. 1998; Maynard et al. 2001; Schottenbauer et al. 2006).

Individuals who used positive religious coping strategies such as benevolent religious reappraisals, collaborative religious coping, seeking spiritual support, to name a few, typically experienced less stress and had higher self-esteem (Pargament et al. 1998). One possible explanation for this finding may be that positive religious coping methods serve a variety of adaptive functions.

One of the most widely used coping methods among Palestinian people is positive religious coping. Which is seen as a mechanism of coping that is "inherently" derived from religious beliefs, practices, experiences, emotions, or relationships (Abu-Raiya and Pargament 2015). Thus, as the spread of COVID-19 threatens to increase levels of stress and anxiety in Palestine, positive religious coping serves some adaptive functions and may lead to some relatively long-term improvements in mental health among people who suffer from stressful and depressive symptoms (Ano and Vasconcelles 2005).

The Islamic religion refers to multiple spiritual beliefs for dealing with crisis and difficult situations. For example, it encourages Muslim believers to accept the crisis and painful events as part of God's wise plan and view crisis as a test from God to deepen one's beliefs. On the other hand, Islamic religion discourages people from "giving up on the mercy of God" and getting involved in self-harm activities (AbuRaiya and Jamal 2019).

Veronese et al. (2018) found that faith in God and the access to those in the therapeutic and religious teaching professions are closely related to religious precepts that can represent a source of motivation to Palestinian psychosocial service providers, protecting them from psychological burden and the risk of dropout.

This study's results are in line with the findings of Gardner et al. (2014) who explored the relationship between perceived stress, quality of life, and positive religious coping in university students. Results revealed that positive religious coping was positively related to quality of life and lack of stress.

The authors' findings are also in keeping with those reported by Maynard et al. (2001) who tested the mediating role of personal religious variables in the use of positive religious coping in threat, loss, and challenge situations. Results showed that personal religious variables played important roles in dealing with stressor situations. 


\section{Limitations}

This study has several limitations which provide opportunities for future studies. First, it focuses on positive religious coping, depressive symptoms, and perceived stress among Palestinian adults. In order to generalize the findings, comparative studies in different context should be accomplished. Second, the study was entirely based on quantitative data collected via self-reporting instruments completed by participants.

Third, positive religious coping and perceived stress scales and their psychometric characteristics had not previously been tested with this specific population and so atypical results cannot be fully ruled out. Fourth, the methods of the present study are correlational and its results are cross-sectional. Consequently, the authors of this study cannot make causal inferences based on its results. Longitudinal and experimental studies are needed to assess the causal connection between these variables.

\section{Conclusion}

The current study supported previous findings demonstrating that positive religious coping was significantly and negatively related to depressive symptoms among a sample of adults in Palestine, while a significant negative correlation was observed between positive religious coping and perceived stress among the participants. The findings of this study suggest many important theoretical and practical implications.

First, the findings imply that assessing the correlation between positive religious coping and depressive symptoms in diverse groups of people in Palestinian society might provide a clearer picture regarding the ways in which Palestinian people use different methods of religious coping to deal with different problems.

Second, the findings also suggest some important practical implications for the mental health and well-being of Palestinians during the spread of COVID-19, especially given that Palestinian society continually faces different types of stressors. It would be important to consider these methods of coping in counseling and other clinical interventions. Psychosocial service providers should develop intervention programs that aim to help people deal with religious/spiritual struggles.

Positive religious strategies may be used with other psychological techniques to improve resilience and well-being among the affected populations; therefore, the role of religious leaders should be a part of healthcare team in dealing with this pandemic, and their influence should be utilized to raise awareness and change negative attitudes and practices among community members (Hashmi et al. 2020).

Third, the Palestinian Ministry of Education should offer more counseling services and effective training for school counselors to help students develop positive problem-solving strategies and take into consideration positive religious techniques to enhance the values of religion tolerance and positivity in dealing with stressful and traumatic situations. Fourth, for universities to offer courses and training for students in clinical and counseling departments concerning intervention during crisis, and to take into consideration the multicultural issues 
in counseling and psychotherapy such as how positive religious copying will increase the effectiveness of future therapeutic and counseling intervention.

Fifth, offering workshops for parents regarding how to help themselves and their children deal with crises and difficult situations and use positive parenting styles that encourage tolerance, sympathy, and positive religious coping in dealing with adversities, such as a global pandemic. Further studies are recommended to test the relationship between current study variables and other related variables that may explain variance in depressive symptoms among adults. It also recommends conducting studies to test the effectiveness of therapeutic programs to deal with stress and depressive symptoms among quarantined people in Palestine during the spread of COVID-19.

\section{Compliance with Ethical Standards}

Conflict of interest The authors declare that they have no conflict of interest.

Ethical Approval All procedures performed in this study involving human participants were in accordance with the ethical standards of University's Research Ethics Board, the American Psychological Association (APA 2010), and with the 1975 Helsinki Declaration.

Informed Consent Informed consent was obtained from all participants.

\section{References}

Abdel-Khalek, A. M., \& Eid, G. K. (2011). Religiosity and its association with subjective well-being and depression among Kuwaiti and Palestinian Muslim children and adolescents. Mental Health, Religion and Culture, 14(2), 117-127. https://doi.org/10.1080/13674670903540951.

Abernethy, A. D., Chang, H. T., Seidlitz, L., Evinger, J. S., \& Duberstein, P. R. (2002). Religious coping and depression among spouses of people with lung cancer. Psychosomatics, 43(6), 456-463. https://doi.org/10.1176/appi.psy.43.6.456.

Abu-El-Noor, M. K. (2017). Assessing spiritual well-being of Palestinian Cardiac Patients: A reflection for a new spiritual care policy. Islamic University of Gaza Journal of Natural and Engineering Studies, 25(3), 53-62.

Abu-El-Noor, N. I., \& Radwan, A. S. (2015). Assessing spiritual well-being of Arab Muslim prostate cancer survivors: A reflection for a new spiritual health care policy. International Journal of Research in Applied Natural and Social Sciences, 3(8), 1-14.

Abu-Raiya, H., Ayten, A., Tekke, M., \& Agbaria, Q. (2019). On the links between positive religious coping, satisfaction with life and depressive symptoms among a multinational sample of Muslims. International Journal of Psychology, 54(5), 678-686. https://doi.org/10.1002/ijop.12521.

Abu-Raiya, H., \& Jamal, H. (2019). The links between religious coping and subjective well-being among Israeli-Muslims who lost a beloved person through death. Death Studies. https://doi. org/10.1080/07481187.2019.1626951.

Abu-Raiya, H., \& Pargament, K. I. (2015). Religious coping among diverse religions: Commonalities and divergences. Psychology of Religion and Spirituality, 7(1), 24-33. https://doi.org/10.1037/ a0037652.

Abu-Raiya, H., Pargament, K. I., Krause, N., \& Ironson, G. (2015). Robust links between religious/ spiritual struggles, psychological distress, and well-being in a national sample of American adults. American Journal of Orthopsychiatry, 85(6), 565-575. https://doi.org/10.1037/ort00 00084. 
Abu-Raiya, H., Pargament, K. I., Mahoney, A., \& Stein, C. (2008). A psychological measure of Islamic religiousness: Development and evidence of reliability and validity. International Journal for the Psychology of Religion, 18(4), 291-315. https://doi.org/10.1080/105086108022292 70.

Abu-Raiya, H., Sasson, T., Pargament, K. I., \& Rosmarin, D. H. (2020). Religious coping and health and well-being among Jews and Muslims in Israel. The International Journal for the Psychology of Religion, 30(3), 202-215. https://doi.org/10.1080/10508619.2020.1727692.

Agbaria, Q. (2014). Depression among Muslim Arab students: The contribution of spiritual, social, and cognitive factors. Psychology Research, 4(6), 428-440. https://doi.org/10.17265 /2159-5542/2014.06.003.

Ahles, J. J., Mezulis, A. H., \& Hudson, M. R. (2016). Religious coping as a moderator of the relationship between stress and depressive symptoms. Psychology of Religion and Spirituality, 8(3), 228-234. https://doi.org/10.1037/rel0000039.

Ahrens, C. E., Abeling, S., Ahmad, S., \& Hinman, J. (2010). Spirituality and well-being: The relationship between religious coping and recovery from sexual assault. Journal of Interpersonal Violence, 25(7), 1242-1263. https://doi.org/10.1177/0886260509340533.

Almuhtaseb, M. I., Alby, F., Zucchermaglio, C., \& Fatigante, M. (2020). Religiosity as a cultural resource for Arab-Palestinian women's coping with cancer. Thoudand Oaks, CA: Sage. https:// doi.org/10.1177/2158244019898730.

American Psychological Association. (2010). Publication manual of the APA (6th ed.). Washington, DC: American Psychological Association.

Ammerman, B., Burke, T., Jacobucci, R., \& McClure, K. (2020). Preliminary investigation of the association between covid-19 and suicidal thoughts and behaviors in the U.S. 2020. PsyArXiv. https://doi.org/10.31234/osf.io/68djp.

Andresen, E. M., Malmgren, J. A., Carter, W. B., \& Patrick, D. L. (1994). Screening for depression in well older adults: Evaluation of a short for of the CES-D. American Journal of Preventive Medicine, 10(2), 77-84. https://doi.org/10.1016/S0749-3797(18)30622-6.

Ano, G. G., \& Vasconcelles, E. B. (2005). Religious coping and psychological adjustment to stress: A meta-analysis. Journal of Clinical Psychology, 61(4), 461-480. https://doi.org/10.1002/ jclp. 20049.

Areba, E. M., Duckett, L., Robertson, C., \& Savik, K. (2018). Religious coping, symptoms of depression and anxiety, and well-being among Somali college students. Journal of Religion and Health, 57(1), 94-109. https://doi.org/10.1007/s10943-017-0359-3.

Arévalo, S., Prado, G., \& Amaro, H. (2008). Spirituality, sense of coherence, and coping responses in women receiving treatment for alcohol and drug addiction. Evaluation and Program Planning, 31(1), 113-123. https://doi.org/10.1016/j.evalprogplan.2007.05.009.

Assari, S. (2014). Chronic medical conditions and major depressive disorder: Differential role of positive religious coping among African Americans, Caribbean Blacks and non-Hispanic Whites. International Journal of Preventive Medicine, 5(4), 405-413.

Azaiza, F., \& Cohen, M. (2008). Between traditional and modern perceptions of breast and cervical cancer screenings: A qualitative study of Arab women in Israel. Psycho-Oncology, 17(1), 34-41. https://doi.org/10.1002/pon.1180.

Braam, A. W., Schrier, A. C., Tuinebreijer, W. C., Beekman, A. T. F., Dekker, J. J. M., \& de Wit, M. A. S. (2010). Religious coping and depression in multicultural Amsterdam: A comparison between native Dutch citizens and Turkish, Moroccan and Surinamese/Antillean migrants. Journal of Affective Disorders, 125(1-3), 269-278. https://doi.org/10.1016/j.jad.2010.02.116.

Carleton, R. A., Esparza, P., Thaxter, P. J., \& Grant, K. E. (2008). Stress, religious coping resources, and depressive symptoms in an urban adolescent sample. Journal for the Scientific Study of Religion, 47(1), 113-121. https://doi.org/10.1111/j.1468-5906.2008.00395.x.

Carpenter, T. P., Laney, T., \& Mezulis, A. (2012). Religious coping, stress, and depressive symptoms among adolescents: A prospective study. Psychology of Religion and Spirituality, 4(1), 19-30. https://doi.org/10.1037/a0023155.

Chan, C. S., \& Rhodes, J. E. (2013). Religious coping, posttraumatic stress, psychological distress, and posttraumatic growth among female survivors four years after Hurricane Katrina. Journal of Traumatic Stress, 26(2), 257-265. https://doi.org/10.1002/jts.21801.

Cohen, S., Kamarck, T., \& Mermelstein, R. (1983). A global measure of perceived stress. Journal of Health and Social Behavior, 24(4), 385-396. https://doi.org/10.2307/2136404. 
Cruz, J. P., Colet, P. C., Qubeilat, H., Al-Otaibi, J., Coronel, E. I., \& Suminta, R. C. (2016). Religiosity and health-related quality of life: A cross-sectional study on Filipino Christian hemodialysis patients. Journal of Religion and Health, 55(3), 895-908. https://doi.org/10.1007/s1094 3-018-0642-y.

De Quervain, D., Aerni, A., Amini, E., Bentz, D., Coynel, D., Gerhards, C., \& Schlitt, T. (2020). The Swiss corona stress study. [Preprint]. https://doi.org/10.31219/osf.io/jqw6a.

Feder, A., Ahmad, S., Lee, E. J., Morgan, J. E., Singh, R., Smith, B. W., et al. (2013). Coping and PTSD symptoms in Pakistani earthquake survivors: Purpose in life, religious coping and social support. Journal of Affective Disorders, 147(1-3), 156-163. https://doi.org/10.1016/j.jad.2012.10.027.

Fernandez, A., \& Loukas, A. (2013). Acculturation and religious coping as moderators of the association between discrimination and depressive symptoms among Mexican-American vocational students. Journal of Immigrant and Minority Health, 16(6), 1290-1293. https://doi.org/10.1007/s1090 3-013-9952-z.

Gardner, T. M., Krägeloh, C. U., \& Henning, M. A. (2014). Religious coping, stress, and quality of life of Muslim university students in New Zealand. Mental Health, Religion and Culture, 17(4), 327-338. https://doi.org/10.1080/13674676.2013.804044.

Goldblatt, H., Cohen, M., Azaiza, F., \& Manassa, R. (2012). Being within or being between? The cultural context of Arab women's experience of coping with breast cancer in Israel. Psycho-Oncology, 22(4), 869-875. https://doi.org/10.1002/pon.3078.

Hashmi, F. K., Iqbal, Q., Haque, N., \& Saleem, F. (2020). Religious cliché and stigma: A brief response to overlooked barriers in COVID-19 management. Journal of Religion and Health. https://doi. org/10.1007/s10943-020-01063-y.

Hebert, R., Zdaniuk, B., Schulz, R., \& Scheier, M. (2009). Positive and negative religious coping and well-being in women with breast cancer. Journal of Palliative Medicine, 12(6), 537-545. https://doi. org/10.1089/jpm.2008.0250.

Henslee, A. M., Coffey, S. F., Schumacher, J. A., Tracy, M., Norris, H. F., \& Galea, S. (2015). Religious coping and psychological and behavioral adjustment after Hurricane Katrina. The Journal of psychology, 149(6), 630-642. https://doi.org/10.1080/00223980.2014.953441.

Holt, C. L., Clark, E. M., Debnam, K. J., \& Roth, D. L. (2014). Religion and health in African Americans: The role of religious coping. American Journal of Health Behavior, 38(2), 190-199. https:// doi.org/10.5993/AJHB.38.2.4.

Horton, K. D., \& Loukas, A. (2013). Depressive symptoms, religious coping, and cigarette smoking among post-secondary vocational students. Psychology of Addictive Behaviors, 27(3), 705-713. https://doi.org/10.1037/a0031195.

Hossain, M. M., Sultana, A., \& Purohit, N. (2020). Mental health outcomes of quarantine and isolation for infection prevention: A systematic umbrella review of the global evidence. Epidemiol Health. https://doi.org/10.2139/ssrn.3561265.

Ibrahim, A. (2020). Therapeutic approach towards suicide among Muslim folks: A treatise during COVID-19 outbreak. African Journal of Biology and Medical Research, 3(2), 26-32.

Khan, Z. H., \& Watson, P. J. (2006). Construction of the Pakistani religious coping practices scale: Correlations with religious coping, religious orientation, and reactions to stress among Muslim university students. International Journal for the Psychology of Religion, 16(2), 101-112. https://doi. org/10.1207/s15327582ijpr1602_2.

Koenig, H. G. (2020). Ways of protecting religious older adults from the consequences of COVID19. The American Journal of Geriatric Psychiatry, 28(7), 776-779. https://doi.org/10.1016/j. jagp.2020.04.004.

Koenig, H. G., George, L. K., \& Siegler, I. C. (1988). The use of religion and other emotion-regulating coping strategies among older adults. The Gerontologist, 28(3), 303-310. https://doi.org/10.1093/ geront/28.3.303.

Kopacz, M. S., Currier, J. M., Drescher, K. D., \& Pigeon, W. R. (2016). Suicidal behavior and spiritual functioning in a sample of veterans diagnosed with PTSD. Journal of Injury and Violence Research, 8(1), 6-14. https://doi.org/10.5249/jivr.v8i1.728.

Lazarus, R. S. (1990). Theory-based stress measurement. Psychological Inquiry, 1(1), 3-13. https://doi. org/10.1207/s15327965pli0101_1.

Lee, Y. (2014). The relationship of spiritual well-being and involvement with depression and perceived stress in Korean nursing students. Global Journal of Health Science, 6(4), 169-176. https://doi. org/10.5539/gjhs.v6n4p169. 
Lee, M., Nezu, A. M., \& Nezu, C. M. (2014). Positive and negative religious coping, depressive symptoms, and quality of life in people with HIV. Journal of Behavioral Medicine, 37(5), 921-930. https ://doi.org/10.1007/s10865-014-9552-y.

Li, S., Wang, Y., Xue, J., Zhao, N., \& Zhu, T. (2020). The impact of COVID-19 epidemic declaration on psychological consequences: A study on active Weibo users. International Journal of Environmental Research and Public Health, 17(6), 2032. https://doi.org/10.3390/ijerph17062032.

Mahamid, F. A. (2020). Collective trauma, quality of life and resilience in narratives of third generation Palestinian refugee children. Child Indicators Research. https://doi.org/10.1007/s12187-020-09739 -3 .

Mahamid, F. A., \& Berte, D. Z. (2019). Social media addiction in geopolitically at-risk youth. International Journal of Mental Health and Addiction, 17(1), 102-111. https://doi.org/10.1007/s1146 9-017-9870-8.

Mahamid, F., \& Berte, D. Z. (2020a). Happiness, sadness, and hope for the future in narratives of Palestinian refugee children. International Journal of Mental Health and Addiction. https://doi. org/10.1007/s11469-020-00303-2.

Mahamid, F. A., \& Berte, D. Z. (2020b). Portrayals of violence and at-risk populations: Symptoms of trauma in adolescents with high utilization of social media. International Journal of Mental Health and Addiction, 18, 980-992. https://doi.org/10.1007/s11469-018-9999-0.

Maltby, J., \& Day, L. (2003). Religious orientation, religious coping and appraisals of stress: Assessing primary appraisal factors in the relationship between religiosity and psychological wellbeing. Personality and Individual Differences, 34(7), 1209-1224. https://doi.org/10.1016/S0191 $-8869(02) 00110-1$.

Maynard, E., Gorsuch, R., \& Bjorck, J. (2001). Religious coping style, concept of God, and personal religious variables in threat, loss, and challenge situations. Journal for the Scientific Study of Religion, 40(1), 65-74. https://doi.org/10.1111/0021-8294.00038.

Min, J. A., Jung, Y. E., Kim, D. J., Yim, H. W., Kim, J. J., Kim, T. S., et al. (2013). Characteristics associated with low resilience in patients with depression and/or anxiety disorders. Quality of Life Research, 22(2), 231-241. https://doi.org/10.1007/s11136-012-0153-3.

Ng, G. C., Mohamed, S., Sulaiman, A. H., \& Zainal, N. Z. (2017). Anxiety and depression in cancer patients: The association with religiosity and religious coping. Journal of Religion and Health, 56(2), 575-590. https://doi.org/10.1007/s10943-016-0267-y.

Ornell, F., Schuch, J. B., Sordi, A. O., \& Kessler, F. H. P. (2020). "Pandemic fear" and COVID-19: Mental health burden and strategies. Brazilian Journal of Psychiatry, 42(3), 232-235. https://doi. org/10.1590/1516-4446-2020-0008.

Palestinian Central Bureau of Statistics. (2019). Palestinians at the End of 2019. Retrieved from http:// www.pcbs.gov.ps/Downloads/book2497.pdf.

Pan, F., Ye, T., Sun, P., Gui, S., Liang, B., Li, L., et al. (2020). Time course of lung changes on chest CT during recovery from 2019 novel coronavirus (COVID-19) pneumonia. Radiology, 295(3), 715721. https://doi.org/10.1148/radiol.2020200370.

Pargament, K. I., Smith, B. W., Koenig, H. G., \& Perez, L. (1998). Patterns of positive and negative religious coping with major life stressors. Journal for the Scientific Study of Religion, 37(4), 710-724. https://doi.org/10.2307/1388152.

Pargament, K. I., Tarakeshwar, N., Ellison, C. G., \& Wulff, K. M. (2001). Religious coping among the religious: The relationships between religious coping and well-being in a national sample of Presbyterian clergy, elders, and members. Journal for the Scientific Study of Religion, 40(3), 497-513. https://doi.org/10.1111/0021-8294.00073.

Pedersen, H. F., Pargament, K. I., Pedersen, C. G., \& Zachariae, R. (2013). Religious coping and quality of life among severely ill lung patients in a secular society. International Journal for the Psychology of Religion, 23(3), 188-203. https://doi.org/10.1080/10508619.2012.728068.

Peres, M. F. P., Kamei, H. H., Tobo, P. R., \& Lucchetti, G. (2018). Mechanisms behind religiosity and spirituality's effect on mental health, quality of life and well-being. Journal of Religion and Health, 57(5), 1842-1855. https://doi.org/10.1007/s10943-017-0400-6.

Qiu, J., Shen, B., Zhao, M., Wang, Z., Xie, B., \& Xu, Y. (2020). A nationwide survey of psychological distress among Chinese people in the COVID-19 epidemic: Implications and policy recommendations. General Psychiatry, 33(2), e100213. https://doi.org/10.1136/gpsych-2020-100213.

Ramirez, S. P., Macêdo, D. S., Sales, P. M. G., Figueiredo, S. M., Daher, E. F., Araújo, S. M., et al. (2012). The relationship between religious coping, psychological distress and quality of life in hemodialysis 
patients. Journal of Psychosomatic Research, 72(2), 129-135. https://doi.org/10.1016/j.jpsychores .2011.11.012.

Rosmarin, D. H., Bigda-Peyton, J. S., Öngur, D., Pargament, K. I., \& Björgvinsson, T. (2013). Religious coping among psychotic patients: Relevance to suicidality and treatment outcomes. Psychiatry Research, 210(1), 182-187. https://doi.org/10.1016/j.psychres.2013.03.023.

Schaefer, C. A., \& Gorsuch, R. L. (1993). Situational and personal variations in religious coping. Journal for the Scientific Study of Religion, 32(2), 136-147. https://doi.org/10.2307/1386793.

Schottenbauer, M. A., Klimes-Dougan, B., Rodriguez, B. F., Arnkoff, D. B., Glass, C. R., \& LaSalle, V. H. (2006). Attachment and affective resolution following a stressful event: General and religious coping as possible mediators. Mental Health, Religion and Culture, 9(5), 448-471. https://doi. org/10.1080/13694670500440684.

Sohrabi, C., Alsafi, Z., O'Neill, N., Khan, M., Kerwan, A., Al-Jabir, A., et al. (2020). World Health Organization declares global emergency: A review of the 2019 novel coronavirus (COVID-19). International Journal of Surgery, 76, 71-76. https://doi.org/10.1016/j.ijsu.2020.02.034.

Stankovska, G., Memedi, I., \& Dimitrovski, D. (2020). Coronavirus COVID-19 disease, mental health and psychological support. Society Register, 4(2), 33-48. https://doi.org/10.14746/sr.2020.4.2.03.

Thabet, A. A. M. (2017). Trauma, mental health, coping, resilience, and post traumatic growth (PG)Palestinian experience. JOJ Nursing and Health Care, 2(2), 1-14. https://doi.org/10.19080/jojnh c.2017.02.555583.

Thabet, A. M., Thabet, S. S., \& Vostanis, P. (2016). The relationships between mental health problems and family coping strategies among Palestinian in the Gaza Strip. Journal of Advances in Medicine and Medical Research, 17(8), 1-11. https://doi.org/10.9734/BJMMR/2016/27747.

Veronese, G., Pepe, A., Dagdukee, J., \& Yaghi, S. (2018). Teaching in conflict settings: Dimensions of subjective wellbeing in Arab teachers living in Israel and Palestine. International Journal of Educational Development, 61, 16-26. https://doi.org/10.1016/j.ijedudev.2017.11.009.

World Health Organization (WHO). Novel Coronavirus situation. https://experience.arcgis.com/exper ience/685d0ace521648f8a5beeeee1b9125cd (10 March 2020, date last accessed).

Xu, Z., Shi, L., Wang, Y., Zhang, J., Huang, L., Zhang, C., et al. (2020). Pathological findings of COVID19 associated with acute respiratory distress syndrome. The Lancet Respiratory Medicine, 8(4), 420-422. https://doi.org/10.1016/S2213-2600(20)30076-X.

Zou, K. H., \& Hall, W. J. (2002). On estimating a transformation correlation coefficient. Journal of Applied Statistics, 29(5), 745-760. https://doi.org/10.1080/02664760120098801.

Zou, K. H., Tuncali, K., \& Silverman, S. G. (2003). Correlation and simple linear regression. Radiology, 227(3), 617-628. https://doi.org/10.1148/radiol.2273011499.

Publisher's Note Springer Nature remains neutral with regard to jurisdictional claims in published maps and institutional affiliations.

\section{Affiliations}

\section{Fayez Azez Mahamid ${ }^{1}$ (i) $\cdot$ Dana Bdier ${ }^{1}$}

Fayez Azez Mahamid

mahamid@najah.edu

1 Psychology and Counseling Department, An-Najah National University, Nablus, Palestine 